\title{
Failure of the Nemo Trial: Bumetanide Is a Promising Agent to Treat Many Brain Disorders but Not Newborn Seizures
}

\author{
Yehezkel Ben-Ari ${ }^{1 *}$, Philippe Damier ${ }^{2}$ and Eric Lemonnier ${ }^{3}$ \\ ${ }^{1}$ INMED - Institut National de la Santé et de la Recherche Médicale U901, Aix-Marseille University, Marseilles, France, \\ ${ }^{2}$ Institut National de la Santé et de la Recherche Médicale, Centre d'Investigation Clinique 0004, Nantes, France, ${ }^{3}$ Hôpital Le \\ Cluzeau, CHU Limoges, Limoges, France
}

The diuretic bumetanide failed to treat acute seizures due to hypoxic ischemic encephalopathy (HIE) in newborn babies and was associated with hearing loss (NEMO trial, Pressler et al., 2015). On the other hand, clinical and experimental observations suggest that the diuretic might provide novel therapy for many brain disorders including Autism Spectrum Disorders (ASD), schizophrenia, Rett syndrome, and Parkinson disease. Here, we discuss the differences between the pathophysiology of severe

OPEN ACCESS

Edited by:

Hansen Wang,

University of Toronto, Canada

Reviewed by:

Daniela Tropea,

Trinity College Dublin, Ireland

Annalisa Scimemi,

State University of New York Albany,

USA

Lucia Ciranna,

Università di Catania, Italy

*Correspondence:

Yehezkel Ben-Ari

yehezkel.ben-ari@inserm.fr

Received: 15 February 2016

Accepted: 21 March 2016

Published: 14 April 2016

Citation:

Ben-Ari Y, Damier P and Lemonnier E

(2016) Failure of the Nemo Trial:

Bumetanide Is a Promising Agent to

Treat Many Brain Disorders but Not

Newborn Seizures.

Front. Cell. Neurosci. 10:90.

doi: 10.3389/fncel.2016.00090 recurrent seizures in the neonates and neurological and psychiatric disorders stressing the uniqueness of severe seizures in newborn in comparison to other disorders.

Keywords: GABA, bumetanide, epilepsy, autism, parkinson disease, clinical trials

Whereas in adult (mature) neurons GABA provides most of the inhibitory tone, in immature neurons it depolarizes and often excites due to higher levels of intracellular chloride $\left(\left(\mathrm{Cl}^{-}\right)_{\mathrm{I}}\right)$ (Ben-Ari et al., 1989, 2007; Ben-Ari, 2014). Extensive investigations suggest that the two chloride co-transporters NKCC1 and KCC2 play a central role in this developmental sequence. NKCC1 and KCC2 are respectively important chloride importers and exporters and the activity of the former early on is thought to underlie the depolarizing and often excitatory actions of GABA on immature neurons (reviewed in Ben-Ari, 2014). High $\left(\mathrm{Cl}^{-}\right)_{\mathrm{I}}$ levels, depolarizing and excitatory actions of GABA are also observed after a wide range of insults and disorders including seizures, Autism Spectrum Disorders (ASD), chronic pain, spinal chord lesions, Down's syndrome, brain trauma, cerebral edema formation, cerebral artery occlusion, and diabetic ketoacidosis (Ben-Ari et al., 2007; Boulenguez et al., 2010; Pizzarelli and Cherubini, 2011; Ben-Ari, 2014; Deidda et al., 2014; Kaila et al., 2014). Therefore, drugs that restore low $\left(\mathrm{Cl}^{-}\right)_{\mathrm{I}}$ levels may provide novel therapies for a wide range of disorders. The diuretic bumetanide is one such drug that specifically blocks the NKCC1 chloride importer thereby reducing $\left(\mathrm{Cl}^{-}\right)_{\mathrm{I}}$ levels and restoring GABAergic inhibition in many neuronal types in physiological and pathological conditions. The recent failure of the NEMO trial aimed at treating seizures in newborn babies with bumetanide (Pressler et al., 2015) has casted some doubts on the therapeutic promises of bumetanide and magnified its side effects. Here, we would like to discuss why this view is not tenable; namely the major differences between the pathogenesis of acute neonatal seizures due to HIE and other disorders, in addition to the good tolerability of bumetanide reported over the last four decades. 
NEMO (Pressler et al., 2015) was a phase I/II trial to assess the safety and optimal dose of bumetanide for the treatment of acute neonatal seizures not responding to a loading dose of phenobarbital. Newborn babies were treated with the diuretic in adjunct to a second dose of phenobarbital. Bumetanide did not reach the primary endpoint $(\geq 80 \%$ reduction in EEG seizure burden without the need for rescue antiepileptic drugs in $>50 \%$ of the patients). The trial was terminated prematurely because of hearing loss observed in 3 out of 11 surviving babies. The hearing loss can be ascribed to synergetic effects of several factors such as immaturity of hair cells, differences between the roles of NKCC1 and KCC2 in the regulation of $\left(\mathrm{Cl}^{-}\right)_{\mathrm{I}}$ in immature and adult cochlear hair cells, and effects of hypoxic injury and toxicity of aminoglycosides that are aggravated by bumetanide (Brummett, 1981; Lu et al., 1999; Zhang et al., 2007; Abbas and Whitfield, 2009; Milenković and Rübsamen, 2011; Wong et al., 2013; Witte et al., 2014). Pressler and colleagues discuss these issues at length stressing the difficulties of evaluating the potential risks/benefit ratio in babies in severe life threatening conditions. Bumetanide has been used including in preterm babies and young children without ototoxicity previously (Flamenbaum and Friedman, 1982; Laughon et al., 2015). Bumetanide is a welltolerated diuretic used to treat hypertension and cerebral edema at all ages; its adverse effects are almost entirely restricted to its diuretic effect such as hypotension and hypokalemia (Asbury et al., 1972; Narins and Chusid, 1986) which are usually easy to correct. Therefore, the ototoxic effect seen in the NEMO study is specific to this age group with the additional risk factors mentioned above.

Furthermore, the poor antiepileptic efficacy in the NEMO trial cannot necessarily be extrapolated to other types of seizures. Bumetanide blocks seizures in some animal models but not others (Ben-Ari et al., 2007; Kilb et al., 2007; Nardou et al., 2009; Ben-Ari, 2014) suggesting that the efficacy of bumetanide is seizure type dependent. In addition, GABA exerts excitatory actions in some models of migration disorders but not in others (Isaev et al., 2005; Tyzio et al., 2009; Pressler et al., 2015). For instance, in human resected slices after surgical interventions, bumetanide reduced hyperactivity in temporal lobe epilepsy (Cohen et al., 2006; Pallud et al., 2014) but not in Sturge-Weber Syndrome where GABA inhibits neuronal activity (Tyzio et al., 2009). In a case report, bumetanide reduced seizure burden in adult temporal lobe epilepsies (Eftekhari et al., 2013; Pressler et al., 2015). For clinical trials in neonatal seizures like NEMO, the regulatory authorities and ethic committees request that the administration of a new drug (such as bumetanide) is only given once phenobarbital has failed to stop seizures. Staley and coworkers have advocated the use of bumetanide and phenobarbital as the former augmented the efficacy of the latter (Dzhala et al., 2005, 2008; Wong et al., 2013). However, these observations are significantly hampered by the lack of investigations of the dynamic alterations of chloride regulation that occur with recurrent seizures. Indeed, using a triple chamber with the two interconnected intact hippocampi and their connecting commissures in three different chambers, we have determined the alterations of GABAergic polarity after a determined number of seizures. The regulation of $\left(\mathrm{Cl}^{-}\right)_{\mathrm{I}}$ levels was found to be highly seizure history dependent. Bumetanide neither prevented the formation by recurrent seizures of an epileptogenic mirror focus nor efficiently reduced their generation (Nardou et al., 2009, 2011; Milenković and Rübsamen, 2011). Recurrent seizures transformed the actions of GABA from inhibition to excitation and phenobarbital blocked initial seizures but aggravated late ones by reinforcing the excitatory actions of GABA (Figure 1; Abbas and Whitfield, 2009; Nardou et al., 2011). This preparation is not readily transposed to human health hence the need of clinical trials. The logistics of clinical trials in a neonatal intensive care setting as well as the population size of the NEMO trial precludes a detailed analysis of the history of seizures prior to bumetanide administration. In addition, the impossibility to use bumetanide as first intention to treat also strongly hampered the conclusions of the trial. All these factors must be included in any evaluation of antiepileptic actions of bumetanide and in particular the need to use it very shortly after the inaugurating seizures. Collectively they suggest that bumetanide might reduce the severity of some seizures but neither apply to all types nor prevent the long term effects of repeated seizures and as such be inefficient as an antiepileptic agent. In contrast to the results of the NEMO trial, clinical and experimental observations suggest that bumetanide might constitute a therapeutic tool to attenuate several seemingly different brain disorders.

\section{AUTISM SPECTRUM DISORDERS (ASD)}

In naive animals, there is an oxytocin mediated abrupt fall of chloride restricted to the delivery period endowed with neuroprotective actions on the new born brain (Tyzio et al., 2006; Witte et al., 2014). This is abolished in an animal model of ASD and in fragile X (Brummett, 1981; Tyzio et al., 2014) and maternal administration of bumetanide restored in off springs physiological $\left(\mathrm{Cl}^{-}\right)_{\mathrm{I}}$ levels and attenuated electrical and behavioral parameters (Eftekhari et al., 2014; Tyzio et al., 2014). Neocortical neurons have elevated $\left(\mathrm{Cl}^{-}\right)_{\mathrm{I}}$ levels and excitatory GABA (He et al., 2014). Bumetanide attenuated the severity of ASD in 5-11 years old children in a double blind, randomized study (Lemonnier et al., 2012). Similar observations were made in a pilot case report (Lemonnier et al., 2013). In an open-label trial pilot study in adolescents with ASD treatment with bumetanide was associated with improved emotion recognition and activation of brain regions involved in social and emotional perception in functional magnetic resonance imaging and neuropsychological testing (Hadjikhani et al., 2015). Bumetanide also ameliorated sensory perception in children/adolescents with ASD (Hadjikhani et al., 2015) and altered EEG features (Bruining et al., 2015). Interestingly, in contrast to seizures, benzodiazepines in ASD appear not to be a negative factor for the use of bumetanide; this suggests that chloride-regulating mechanisms are not severely affected in ASD. Behavioral scores of ASD are more efficiently attenuated by a combined educative and bumetanide treatment than by educative/placebo treatment ( $\mathrm{Du}$ et al., 2015). Interestingly, oxytocin spray that reduces communication deficits (Guastella et al., 2008) act like bumetanide by reducing $\left(\mathrm{Cl}^{-}\right)_{\mathrm{I}}$ levels (Tyzio 

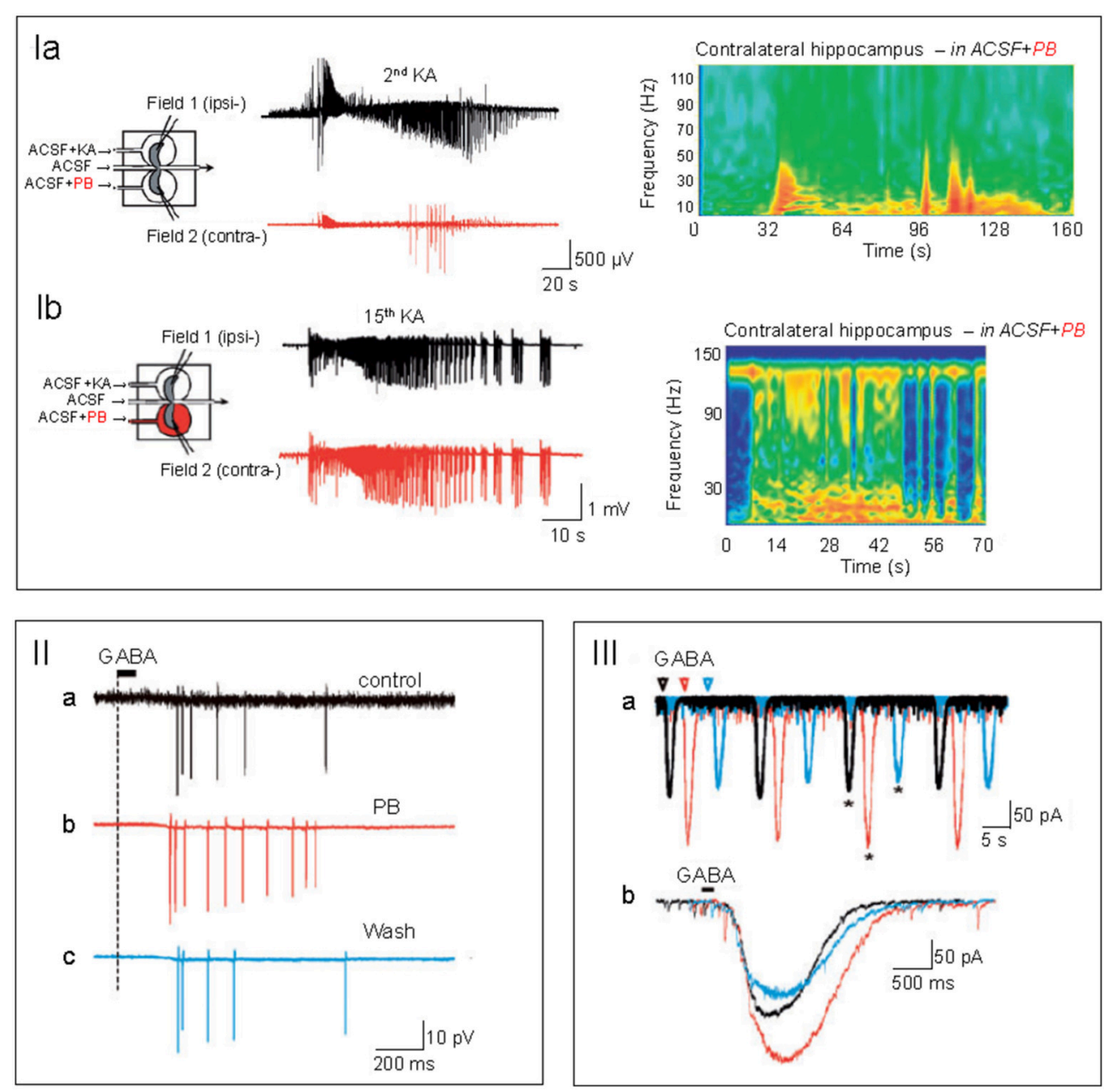

FIGURE 1 | (I) Phenobarbital (PB) attenuates early seizures but aggravates late ones. In a triple chamber with the 2 intact hippocampi interconnected by their commissural connections in vitro, kainate was applied to one hippocampus generating interictal and ictal discharges in the ipsi-lateral hippocampus (dark trace) that propagated to the contralateral hippocampus.PB application to the contralateral hippocampus (red trace) blocked the initial paroxysmal activity, (la) but aggravated them when first applied after 15 recurrent ictal and interictal discharges (lb). Right side: time frequency power plots to illustrate the different effects after a single and any recurrent ictal and interictal discharges. Note the exclusively low frequency events recorded initially in the PB treated hippocampus and the enhanced high frequency events observed after 15 paroxysmal activities. In (Ila-c), spikes evoked in the contralateral hippocampus by focal applications of GABA in the presence of glutamate receptor antagonists. Intact hippocampus subjected to many recurrent Ilds and IDs. PB (red) increased the number of spikes in comparison to control (Ila-dark) and wash out (IIc-blue). (IIla,b) Superimposed perforated-patch recordings of the currents evoked by GABA before (Ila-black), during (Illb-red), and after PB wash out (Ilc-blue) in the presence of antagonists of glutamate receptors. Note the enhanced GABA currents produced by PB (taken with permission from Nardou et al., 2011).

et al., 2006). The effect of bumetanide on seizures that occur in many children with ASD has not been determined as children with epilepsies were not included in these trials.

\section{SCHIZOPHRENIA}

There is no suitable acceptable animal model of schizophrenia, hence the difficulty in determining chloride equilibrium and intracellular levels. But there is some indirect evidence that chloride co-transporters might be affected. Thus, in human and animal models, there is a reduction of the expression of chloride co-transporters (Arion and Lewis, 2011; Hyde et al.,
2011; Kalkman, 2011). Also, drugs known to reduce $\left(\mathrm{Cl}^{-}\right)_{\mathrm{I}}$ levels notably oxytocin attenuate schizophrenia symptoms (CacciottiSaija et al., 2015; Strauss et al., 2015). In a pilot case study, we tested the effects of bumetanide in a patient suffering from hallucinations and schizophrenia. We found a significant long lasting reduction of the hallucinations; these recur when the treatment was stopped (Lemonnier et al., 2016).

\section{PARKINSON DISEASE}

In 2 animal models of Parkinson Disease (PD), striatal medium spiny neurons generated Giant GABAergic 
TABLE 1 | Effects of bumetanide on Parkinsonian motor symptoms in 4 patients.

\begin{tabular}{|c|c|c|c|c|c|c|c|c|}
\hline \multirow[t]{2}{*}{ Cases } & \multicolumn{2}{|c|}{ UPDRS III (OFF) } & \multicolumn{2}{|c|}{ UPDRS II (OFF) } & \multirow[t]{2}{*}{ Patient's main clinical effect } & \multicolumn{2}{|c|}{ Potassium } & \multirow[t]{2}{*}{ Side effects } \\
\hline & Baseline & $\begin{array}{l}\text { After } 2 \text { mo of } \\
\text { bumetanide }\end{array}$ & Baseline & $\begin{array}{l}\text { After } 2 \text { mo of } \\
\text { bumetanide }\end{array}$ & & Baseline & $\begin{array}{l}\text { After } 2 \text { mo of } \\
\text { bumetanide }\end{array}$ & \\
\hline 1 & 44 & 29 & 30 & 18 & Improvement of parkinsonism & 3.9 & 3.8 & None \\
\hline 2 & 25 & 11 & 15 & 10 & No change & 4.1 & 4.2 & Mild polyuria \\
\hline \multirow[t]{2}{*}{$3^{\star}$} & 29 & 26 & 39 & 33 & Improvement of gait & 4.4 & 4.2 & Mild polyuria \\
\hline & & & & & & & & Fatigue \\
\hline 4 & 43 & 34 & 31 & 26 & Improvement of balance & 3.8 & 4.1 & Moderate polyuria \\
\hline
\end{tabular}

They were treated for 2 months with the diuretic. Reproduced from (Damier et al., 2016).

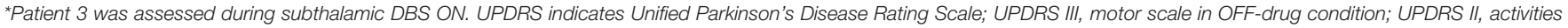
of daily living in the worst conditions (OFF).

Currents that are readily blocked by L-Dopa and lesions of the sub thalamic nucleus suggesting that they constitute relevant signatures of PD (Dehorter et al., 2009, 2012). In a pilot open trial, bumetanide improved gait and reduced freezing in four patients with PD (Damier et al., 2016). Interestingly, bumetanide seems to exert beneficial effects on gait abnormalities and freezing of gait observed in two of these patients (Table 1). These encouraging preliminary observation need to be confirmed in further controlled trials.

\section{RETT SYNDROME}

Rett syndrome includes autistic features and has been often listed in ASD in several studies. Expression of the Mecp2 mutation exclusively in GABAergic interneurons generates several features of Rett syndrome stressing their roles in Rett syndrome pathogenesis (Calfa et al., 2014). In addition, the levels of KCC2 and NKCC1 in the CSF of children with Rett syndrome are respectively reduced and enhanced suggesting an alteration of chloride regulation (Duarte et al., 2013). In human neurons transformed from pluripotent cells of patients with Rett syndrome, there is a deficit in KCC2 and a delay in the excitatory to inhibitory GABA switch (Tang et al., 2016). Furthermore, restoring $\mathrm{KCC} 2$ in mecp2 deficient mice rescued GABA deficits.

\section{PAIN}

In a variety of experimental conditions, chloride co-transporters are dys-regulated in motor spasticity, morphine-induced hyperalgesia and chronic pain, and KCC2 activating agents attenuate their severity (Boulenguez et al., 2010; Gagnon et al., 2013). Oxytocin like bumetanide attenuated pain in pups by reducing $\left(\mathrm{Cl}^{-}\right)_{\mathrm{I}}$ levels in pain pathways (Mazzuca et al., 2011).
In several instances, encouraging preclinical data fail in clinical trials and the reasons for these failures are not always straightforward. They might also lead to the abandon of the animal model although heterogeneity of the clinical data might also be a factor. Yet, with bumetanide, the situation is of particular interest as the convergence of animal and human data is reinforced by a fundamental conceptual series of observations stressing the impact of a wide range of insults on $\left(\mathrm{Cl}^{-}\right)_{\mathrm{I}}$ levels paving the way to a common therapeutic strategy to many disorders. Therefore, neither the severe side effects of bumetanide on the hearing system of newborn with hypoxic ischemic encephalopathy (HIE) nor its lack of efficacy in the NEMO study bear relevance to many other disorders. High $\left(\mathrm{Cl}^{-}\right)_{\mathrm{I}}$ levels and excitatory GABA play a fundamental role in the pathogenesis of many disorders, generating aberrant activities that perturb the operation of behaviorally relevant oscillations. Bumetanide and other drugs acting on chloride co-transporters can restore low $\left(\mathrm{Cl}^{-}\right)_{\mathrm{I}}$ levels in these disorders but may be contraindicated in newborns because chloride co-transporters are still operative.

\section{AUTHOR CONTRIBUTIONS}

PD and EL contributed to the summary on Parkinson disease and autism respectively and YB performed the analysis of the literature and wrote the paper.

\section{FUNDING}

Experimental work on autism of YB-A was financed by the Bettencourt-Schuller Foundation but grants rejected by the European Research Council. Clinical trials on autism were supported by the Simons Foundation but grants rejected by the Agence Nationale de Recherche.

\section{ACKNOWLEDGMENTS}

I am grateful to R. Pressler for her comments and suggestions. 


\section{REFERENCES}

Abbas, L., and Whitfield, T. T. (2009). Nkcc1 (Slc12a2) is required for the regulation of endolymph volume in the otic vesicle and swim bladder volume in the zebrafish larva. Development 136, 2837-2848. doi: 10.1242/dev.034215

Arion, D., and Lewis, D. A. (2011). Altered expression of regulators of the cortical chloride transporters NKCC1 and KCC2 in schizophrenia. Arch. Gen. Psychiatry 68, 21-31. doi: 10.1001/archgenpsychiatry.2010.114

Asbury, M. J., Gatenby, P. B., O'Sullivan, S., and Bourke, E. (1972). Bumetanide: potent new "loop" diuretic. Br. Med. J. 1, 211-213. doi: 10.1136/bmj.1.5794.211

Ben-Ari, Y. (2014). The GABA excitatory/inhibitory developmental sequence: a personal journey. Neuroscience 279C, 187-219. doi: 10.1016/j.neuroscience.2014.08.001

Ben-Ari, Y., Cherubini, E., Corradetti, R., and Gaiarsa, J. L. (1989). Giant synaptic potentials in immature rat CA3 hippocampal neurones. J. Physiol. 416, 303-325. doi: 10.1113/jphysiol.1989.sp017762

Ben-Ari, Y., Gaiarsa, J.-L., Tyzio, R., and Khazipov, R. (2007). GABA: a pioneer transmitter that excites immature neurons and generates primitive oscillations. Physiol. Rev. 87, 1215-1284. doi: 10.1152/physrev.00017.2006

Boulenguez, P., Liabeuf, S., Bos, R., Bras, H., Jean-Xavier, C., Brocard, C., et al. (2010). Down-regulation of the potassium-chloride cotransporter KCC2 contributes to spasticity after spinal cord injury. Nat. Med. 16, 302-307. doi: $10.1038 / \mathrm{nm} .2107$

Bruining, H., Passtoors, L., Goriounova, N., Jansen, F., Hakvoort, B., de Jonge, M., et al. (2015). Paradoxical benzodiazepine response: a rationale for bumetanide in neurodevelopmental disorders? Pediatrics 136, e539-e543. doi: 10.1542/peds.2014-4133

Brummett, R. E. (1981). Ototoxicity resulting from the combined administration of potent diuretics and other agents. Scand. Audiol. Suppl. 14(Suppl.), 215-224.

Cacciotti-Saija, C., Langdon, R., Ward, P. B., Hickie, I. B., Scott, E. M., Naismith, S. L., et al. (2015). A double-blind randomized controlled trial of oxytocin nasal spray and social cognition training for young people with early psychosis. Schizophr. Bull. 41, 483-493. doi: 10.1093/schbul/sbu094

Calfa, G., Li, W., Rutherford, J. M., and Pozzo-Miller, L. (2014). Excitation/inhibition imbalance and impaired synaptic inhibition in hippocampal area CA3 of Mecp2knockout mice. Hippocampus 25, 159-168. doi: $10.1002 /$ hipo.22360

Cohen, I., Huberfeld, G., and Miles, R. (2006). Emergence of disinhibition-induced synchrony in the CA3 region of the guinea pig hippocampus in vitro. J. Physiol. 570, 583-594. doi: 10.1113/jphysiol.2005.097899

Damier, P., Hammond, C., and Ben-Ari, Y. (2016). Bumetanide to treat parkinson disease: a report of 4 cases. Clin. Neuropharmacol. 39, 57-59. doi: 10.1097/WNF.0000000000000114

Dehorter, N., Guigoni, C., Lopez, C., Hirsch, J., Eusebio, A., Ben-Ari, Y., et al. (2009). Dopamine-deprived striatal GABAergic interneurons burst and generate repetitive gigantic IPSCs in medium spiny neurons. J. Neurosci. 29, 7776-7787. doi: 10.1523/JNEUROSCI.1527-09.2009

Dehorter, N., Lozovaya, N., Mdzomba, B. J., Michel, F. J., Lopez, C., Tsintsadze, V., et al. (2012). Subthalamic lesion or levodopa treatment rescues giant GABAergic currents of PINK1-deficient striatum. J. Neurosci. 32, 18047-18053. doi: 10.1523/JNEUROSCI.2474-12.2012

Deidda, G., Allegra, M., Cerri, C., Naskar, S., Bony, G., Zunino, G., et al. (2014). Early depolarizing GABA controls critical-period plasticity in the rat visual cortex. Nat. Neurosci. 18, 87-96. doi: 10.1038/nn.3890

Du, L., Shan, L., Wang, B., Li, H., Xu, Z., Staal, W. G., et al. (2015). A pilot study on the combination of applied behavior analysis and bumetanide treatment for children with autism. J. Child Adolesc. Psychopharmacol. 25, 585-588. doi: 10.1089/cap.2015.0045

Duarte, S. T., Armstrong, J., Roche, A., Ortez, C., Pérez, A., del Mar O’Callaghan, M., et al. (2013). Abnormal expression of cerebrospinal fluid cation chloride cotransporters in patients with rett syndrome. PLOS ONE 8:e68851. doi: 10.1371/journal.pone.0068851

Dzhala, V. I., Brumback, A. C., and Staley, K. J. (2008). Bumetanide enhances phenobarbital efficacy in a neonatal seizure model. Ann. Neurol. 63, 222-235. doi: 10.1002/ana.21229

Dzhala, V. I., Talos, D. M., Sdrulla, D. A., Brumback, A. C., Mathews, G. C., Benke, T. A., et al. (2005). NKCC1 transporter facilitates seizures in the developing brain. Nat. Med. 11, 1205-1213. doi: 10.1038/nm1301
Eftekhari, S., Mehvari Habibabadi, J., Najafi Ziarani, M., Hashemi Fesharaki, S. S., Gharakhani, M., Mostafavi, H., et al. (2013). Bumetanide reduces seizure frequency in patients with temporal lobe epilepsy. Epilepsia 54, e9-e12. doi: $10.1111 /$ j.1528-1167.2012.03654.x

Eftekhari, S., Shahrokhi, A., Tsintsadze, V., Nardou, R., Brouchoud, C., Conesa, M., et al. (2014). Response to Comment on "Oxytocin-mediated GABA inhibition during delivery attenuates autism pathogenesis in rodent offspring." Science 346, 176-176. doi: 10.1126/science.1256009

Flamenbaum, W., and Friedman, R. (1982). Pharmacology, therapeutic efficacy, and adverse effects of bumetanide, a new "loop" diuretic. Pharmacotherapy 2, 213-222. doi: 10.1002/j.1875-9114.1982.tb03188.x

Gagnon, M., Bergeron, M. J., Lavertu, G., Castonguay, A., Tripathy, S., Bonin, R. P., et al. (2013). Chloride extrusion enhancers as novel therapeutics for neurological diseases. Nat. Med. 19, 1524-1528. doi: 10.1038/nm.3356

Guastella, A. J., Mitchell, P. B., and Dadds, M. R. (2008). Oxytocin increases gaze to the eye region of human faces. Biol. Psychiatry 63, 3-5. doi: 10.1016/j.biopsych.2007.06.026

Hadjikhani, N., Zürcher, N. R., Rogier, O., Ruest, T., Hippolyte, L., Ben-Ari, Y., et al. (2015). Improving emotional face perception in autism with diuretic bumetanide: a proof-of-concept behavioral and functional brain imaging pilot study. Autism 19, 149-157. doi: 10.1177/1362361313514141

He, Q., Nomura, T., Xu, J., and Contractor, A. (2014). The developmental switch in GABA polarity is delayed in fragile X mice. J. Neurosci. 34, 446-450. doi: 10.1523/JNEUROSCI.4447-13.2014

Hyde, T. M., Lipska, B. K., Ali, T., Mathew, S. V., Law, A. J., Metitiri, O. E., et al. (2011). Expression of GABA signaling molecules KCC2, NKCC1, and GAD1 in cortical development and schizophrenia. J. Neurosci. 31, 11088-11095. doi: 10.1523/JNEUROSCI.1234-11.2011

Isaev, D., Isaeva, E., Khazipov, R., and Holmes, G. L. (2005). Anticonvulsant action of GABA in the high potassium-low magnesium model of ictogenesis in the neonatal rat hippocampus in vivo and in vitro 31. J. Neurophysiol. 94, 2987-2992. doi: 10.1152/jn.00138.2005

Kaila, K., Price, T. J., Payne, J. A., Puskarjov, M., and Voipio, J. (2014). Cationchloride cotransporters in neuronal development, plasticity and disease. Nat. Rev. Neurosci. 15, 637-654. doi: 10.1038/nrn3819

Kalkman, H. O. (2011). Alterations in the expression of neuronal chloride transporters may contribute to schizophrenia. Prog. Neuropsychopharmacol. Biol. Psychiatry 35, 410-414. doi: 10.1016/j.pnpbp.2011.01.004

Kilb, W., Sinning, A., and Luhmann, H. J. (2007). Model-specific effects of bumetanide on epileptiform activity in the in-vitro intact hippocampus of the newborn mouse. Neuropharmacology 53, 524-533. doi: 10.1016/j.neuropharm.2007.06.015

Laughon, M. M., Chantala, K., Aliaga, S., Herring, A. H., Hornik, C. P., Hughes, R., et al. (2015). Diuretic exposure in premature infants from 1997 to 2011. Am. J. Perinatol. 32, 49-56. doi: 10.1055/s-0034-1373845

Lemonnier, E., Degrez, C., Phelep, M., Tyzio, R., Josse, F., Grandgeorge, M., et al. (2012). A randomised controlled trial of bumetanide in the treatment of autism in children. Transl. Psychiatry 2:e202. doi: 10.1038/tp. 2012.124

Lemonnier, E., Lazartigues, A., and Ben-Ari, Y. (2016). Treating schizophrenia with the diuretic bumetanide: a case report. Clin. Neuropharmacol. 39, 115-117. doi: 10.1097/WNF.0000000000000136

Lemonnier, E., Robin, G., Degrez, C., Tyzio, R., Grandgeorge, M., and Ben-Ari, Y. (2013). Treating Fragile X syndrome with the diuretic bumetanide: a case report. Acta Paediatr. 102, e288-e290. doi: 10.1111/apa. 12235

Lu, J., Karadsheh, M., and Delpire, E. (1999). Developmental regulation of the neuronal-specific isoform of $\mathrm{K}-\mathrm{Cl}$ cotransporter $\mathrm{KCC} 2$ in postnatal rat brains. J. Neurobiol. 39, 558-568.

Mazzuca, M., Minlebaev, M., Shakirzyanova, A., Tyzio, R., Taccola, G., Janackova, S., et al. (2011). Newborn analgesia mediated by oxytocin during delivery. Front. Cell. Neurosci. 5:3. doi: 10.3389/fncel.2011.00003

Milenković, I., and Rübsamen, R. (2011). Development of the chloride homeostasis in the auditory brainstem. Physiol. Res. 60(Suppl. 1), S15-S27.

Nardou, R., Ben-Ari, Y., and Khalilov, I. (2009). Bumetanide, an NKCC1 antagonist, does not prevent formation of epileptogenic focus but blocks epileptic focus seizures in immature rat hippocampus. J. Neurophysiol. 101, 2878-2888. doi: 10.1152/jn.90761.2008 
Nardou, R., Yamamoto, S., Chazal, G., Bhar, A., Ferrand, N., Dulac, O., et al. (2011). Neuronal chloride accumulation and excitatory GABA underlie aggravation of neonatal epileptiform activities by phenobarbital. Brain 134, 987-1002. doi: 10.1093/brain/awr041

Narins, R. G., and Chusid, P. (1986). Diuretic use in critical care. Am. J. Cardiol. 57, 26A-32A. doi: 10.1016/0002-9149(86)91003-9

Pallud, J., Le Van Quyen, M., Bielle, F., Pellegrino, C., Varlet, P., Labussiere, M., et al. (2014). Cortical GABAergic excitation contributes to epileptic activities around human glioma. Sci. Transl. Med. 6, 244ra89. doi: 10.1126/scitranslmed.3008065

Pizzarelli, R., and Cherubini, E. (2011). Alterations of GABAergic signaling in Autsim Spectrum Disorders. Neural Plast. 2011:297153. doi: $10.1155 / 2011 / 297153$

Pressler, R. M., Boylan, G. B., Marlow, N., Blennow, M., Chiron, C., Cross, J. H., et al. (2015). Bumetanide for the treatment of seizures in newborn babies with hypoxic ischaemic encephalopathy (NEMO): an open-label, dose finding, and feasibility phase 1/2 trial. Lancet Neurol. 14, 469-477. doi: 10.1016/S14744422(14)70303-5

Strauss, G. P., Keller, W. R., Koenig, J. I., Gold, J. M., Frost, K. H., and Buchanan, R. W. (2015). Plasma oxytocin levels predict social cue recognition in individuals with schizophrenia. Schizophr. Res. 162, 47-51. doi: 10.1016/j.schres.2015.01.034

Tang, X., Kim, J., Zhou, L., Wengert, E., Zhang, L., Wu, Z., et al. (2016). KCC2 rescues functional deficits in human neurons derived from patients with Rett syndrome. Proc. Natl. Acad. Sci. U.S.A. 113, 751-756. doi: $10.1073 /$ pnas. 1524013113

Tyzio, R., Cossart, R., Khalilov, I., Minlebaev, M., Hübner, C. A., Represa, A., et al. (2006). Maternal oxytocin triggers a transient inhibitory switch in GABA signaling in the fetal brain during delivery. Science 314, 1788-1792. doi: $10.1126 /$ science. 1133212
Tyzio, R., Khalilov, I., Represa, A., Crépel, V., Zilberter, Y., Rheims, S., et al. (2009). Inhibitory actions of the gamma-aminobutyric acid in pediatric Sturge-Weber syndrome. Ann. Neurol. 66, 209-218. doi: 10.1002/ana.21711

Tyzio, R., Nardou, R., Ferrari, D. C., Tsintsadze, T., Shahrokhi, A., Eftekhari, S., et al. (2014). Oxytocin-mediated GABA inhibition during delivery attenuates autism pathogenesis in rodent offspring. Science 343, 675-679. doi: 10.1126/science. 1247190

Witte, M., Reinert, T., Dietz, B., Nerlich, J., Rübsamen, R., and Milenković, I. (2014). Depolarizing chloride gradient in developing cochlear nucleus neurons: underlying mechanism and implication for calcium signaling. Neuroscience 261, 207-222. doi: 10.1016/j.neuroscience.2013.12.050

Wong, A. B., Jing, Z., Rutherford, M. A., Frank, T., Strenzke, N., and Moser, T. (2013). Concurrent maturation of inner hair cell synaptic $\mathrm{Ca} 2+$ influx and auditory nerve spontaneous activity around hearing onset in mice. J. Neurosci. 33, 10661-10666. doi: 10.1523/JNEUROSCI.1215-13.2013

Zhang, L.-L., Delpire, E., and Vardi, N. (2007). NKCC1 does not accumulate chloride in developing retinal neurons. J. Neurophysiol. 98, 266-277. doi: 10.1152/jn.00288.2007

Conflict of Interest Statement: YB is CEO and share holder of Neurochlore 2 and B\&A Therapeutics biotech companies dedicated to the development of treatments to autism and parkinson disease. EL and PD are respectively share holders of Neurochlore and B\&A Therapeutics.

Copyright (C) 2016 Ben-Ari, Damier and Lemonnier. This is an open-access article distributed under the terms of the Creative Commons Attribution License (CC BY). The use, distribution or reproduction in other forums is permitted, provided the original author(s) or licensor are credited and that the original publication in this journal is cited, in accordance with accepted academic practice. No use, distribution or reproduction is permitted which does not comply with these terms. 